\title{
ОСОБЕННОСТИ ОПРЕДЕЛЕНИЯ ПАРАМЕТРОВ ЗУБНЫХ ДУГ
}

\section{FEATURES OF DETERMINING THE SHAPE AND SIZE OF DENTAL ARCHES}

Summary. Relevance. Currently, in orthodontics, it is difficult to predict the size of dental arches with anomalies of their shape and size. There is very little information on the assessment of the compliance of the sizes of teeth and dental arches with the individual parameters of the head and face. No clear algorithms have been developed for the study of abnormal dental arches to determine the tactics of orthodontic treatment.

The purpose of the study. Improving the efficiency of diagnosis and treatment of occlusion anomalies in patients by optimizing methods for determining the shape and size of dental arches.

Material and methods. The first group included patients with normodontism of permanent teeth, the second group - with macrodontism, and the third group-with microdontism.

In each group, subgroups were identified depending on the gnatic type of dental arches (mesognatic, brachygnatic, and dolichognatic).

Original methods for assessing the dental status that are important for clinical dentistry, in particular for orthodontics, are proposed.
Пуздырева Маргарита Николаевна

К.м.н., ассистент, Санкт-Петербургский государственный педиатрический медицинский университет Министерства здравоохранения РФ seven-spb@yandex.ru

Рожкова Мария Геннадьевна Ассистент, Санкт-Петербургский государственный педиатрический медичинский университет Министерства здравоохранения РФ

rozmaria2010@yandex.ru

Фищев Сергей Борисович

Д.м.н., профессор, Санкт-Петербургский государственный педиатрический медицинский университет Министерства здравоохранения РФ super.kant@yandex.ru

Лепилин Александр Викторович

Д.м.н., профессор, Саратовский государственный медицинский университет имени В.И. Разумовского Министерства здравоохранения РФ lepilins@mail.ru

Севастьянов Аркадий Владимирович

Д.м.н., профессор, Санкт-Петербургский государственный педиатрический медичинский университет Министерства здравоохранения РФ ardy.dkr@mail.ru

Орлова Ирина Викторовна

К.м.н., доцент, Санкт-Петербургский государственный педиатрический медицинский университет Министерства здравоохранения РФ orisha@mail.ru

Субботин Роман Сергеевич

К.м.н., ассистент Санкт-Петербургский государственный педиатрический медицинский университет Министерства здравоохранения РФ roma.seregin.92@mail.ru

Попов Владимир Петрович

К.п.н., ассистент, Санкт-Петербургский государственный педиатрический медицинский университет Министерства здравоохранения РФ vpopov5@mail.ru

Аннотация. Актуальность. В ортодонтии существуют трудности в прогнозировании параметров зубных дуг при аномалиях их размеров и формы. В настоящее время мало сведений о соответствии формы и размеров зубов и зубных арок параметрам головы и лица пациентов. Нет четких последовательных исследований аномальных зубных дуг для рациональной тактики лечения в клинике ортодонтии.

Цель исследования. Оптимизация диагностики и лечения окклюзионных аномалий у пациентов путем создания правильной формы и размеров зубных арок. 
The results of the study. The results of the study of patients with physiological occlusion of permanent teeth showed that in people with normodont types of dental arches, their main linear parameters were different in meso -, brachy-and dolichognathia, despite the uniformity of odontometric indicators. In accordance with the objectives of the study, to determine the effectiveness of diagnostics and optimization of research methods, for us, the most significant value was not the absolute values of linear parameters, but the difference between the actual and calculated values, which had both negative and positive values. Conclusions. We recommend that you determine the dental type of dental arches when comparing three main indicators: the diagonal of the face, the sum of the width of the crowns of fourteen teeth, and the average modulus of the molar crowns. We recommend comparing the gnatic type of the face with the gnatic type of the dental arches to determine the discrepancy between the specified parameters.

Keywords: malocclusion and malformation, shape and size of dental arches, orthodontics.
Материал и методы. Представлены пациенты первой группы с нормодонтизмом постоянных зубов, второй группы - с макродонтизмом, третьей - с микродонтизмом.

Из каждой группы выделили подгруппы с учётом гнатического типа зубных дуг (мезогнатические, брахигнатические и долихогнатические).

Рекомендованы актуальные способы анализа одонтологического статуса, имеющие большое значение как в ортодонтии, так и в клинической стоматологии.

Результаты исследования. Проведенное исследование пациентов с физиологической окклюзией постоянных зубов показало, что у лиц с нормодонтными типами зубных дуг, значимые линейные параметры отличались при мезо-, брахи- и долихогнатии, независимо от одноразмерности одонтометрических показателей. Согласно задачам анализа, определения эффективности диагностики и оптимизации методов исследования, для нас немаловажную ценность имели не абсолютные значения линейных параметров, а разность между фактическими и расчетными параметрами, которые содержали как отрицательные, так и положительные значения.

Выводы. Сравнивая основные три показателя типа зубных арок: диагональ лица, сумма ширины коронок четырнадцати зубов и средний модуль коронок моляров, рекомендуем определять дентальный тип зубных дуг. Для определения несоответствия указанных параметров гнатический тип лица рекомендуем сравнивать с гнатическим типом зубных дуг.

Ключевые слова: аномалии и деформации прикуса, форма и размеры зубных дуг, ортодонтия.

\section{Материал и методы исслеАования}

В исследовании принимали участие жители г. Санкт-Петербурга, 362 человека обоего пола, первого периода зрелого возраста (от 21-35 лет).

Пациенты с нормодонтизмом постоянных зубов были включены в первую группу, во вторую группу с макродонтизмом, в третью-с микродонтизмом.

В зависимости от гнатического типа зубных дуг (мезогнатические, брахигнатические и долихогнатические) из каждой группы были выделены подгруппы.

На лице между точками, общепринятыми при проведении подобных исследований, проводили измерения. По диагональным размерам, а именно проводили измерения между точками «t» (козелок уха) и «sn» подносовая (субназальная) точка, оценивали дентальный тип лица.

Измерения проводили с обеих сторон. Средний показатель диагонали лица определяли в случае различия 
величин. Для нормодонтного типа лица была характерна величина диагонали лица от 122 до 130 мм. Согласно указанным размерам, типы лица были микродонтными при уменьшении величины, а макродонтные - соответственно при увеличении цифровых показателей.

Гнатический индекс, как процентное отношение диагонали лица к его ширине, определяли измерением лица в трансвесальном направлении между козелковыми точками.

Мезогнатическим типам лица соответствовала величина гнатического индекса от 83 до 93. Для брахигнатии характерно уменьшение индексных показателей. Следовательно, для долихогнатических типов лица были типичны увеличенные индексные показатели (более $93 \%)$.

Длину зубной дуги вычисляли как сумму ширины коронок зубов, составляющих зубной ряд. Не включали в исследование зубы мудрости.

Использовали в качестве оценки размеров зубов величину среднего модуля моляров (сумма модулей коронок первого и второго моляров разделенная на два). Для микродонтизма был характерен средний модуль моляров менее 10,6 мм, а для макродонтизма более - 11,0 мм. Модуль рассчитывался как сумма поперечных и продольных размеров коронок моляров, разделенная пополам.

Традиционно по методу Pont A. (1908) или по методу Linder H. и Harth G. (1930) измеряются трансверсальные размеры зубных дуг. Основными ориентирами для оценки размеров зубных дуг в нашем исследовании служили наиболее выпуклые точки вестибулярной поверхности зубов вблизи окклюзионного контура.

Нами разработан алгоритм исследования для определения соразмерности зубов основным параметрам зубных дуг и челюстей, который использовали как для оценки зубных дуг при физиологической окклюзии, так и для диагностики аномалий формы и размеров зубных дуг. При выборе методов лечения аномалий был полезен предложенный алгоритм.

На первом этапе определяли гнатический тип лица. Одонтометрические показатели оценивали на втором этапе. Размеры зубных дуг оценивали на третьем этапе.

Предложенный алгоритм позволил установить соответствие размеров зубов параметрам зубных дуг и выявить аномалии размеров и формы зубных дуг в различных отделах и в целом, по дуге. Сравнить размеры зубных дуг верхней и нижней челюсти между собой.

\section{Результаты \\ исслеАОвания}

Несмотря на одноразмерность одонтометрических показателей результаты исследования пациентов с физиологической окклюзией постоянных зубов показали, что у людей с нормодонтными типами зубных дуг, их основные линейные параметры были различны при мезо, брахи-, долихогнатии.

У людей с мезогнатическим типом зубных дуг фактические величины трансверсальных размеров зубных дуг в области премоляров соответствовали рассчитанным по методу Pont. Ширина зубных дуг при брахигнатии в области премоляров была шире, чем рассчитанная по методу Pont на 2,32 $\pm 0,00$ мм. Трансверсальные размеры у людей с долихогнатическим типом зубных дуг в области премоляров были меньше, чем рассчитанные по методу Pont на 4,95 $\pm 0,00$ мм.

Рассчитанные по методу Linder и Harth трансверсальные размеры зубных дуг в области премоляров, также имели особенности.

У людей с мезогнатическим типом зубных дуг фактические величины трансверсальных размеров зубных дуг в области премоляров были шире, чем рассчитанные по методу Linder и Harth на 2,29 \pm 0,00 мм. При брахигнатии ширина зубных дуг в области премоляров были шире, чем рассчитанная по методу Linder и Harth на 4,67 \pm 0,00 мм. Трансверсальные размеры зубных дуг у людей с долихогнатичесим типом зубных дуг в области премоляров были меньше, чем рассчитанные

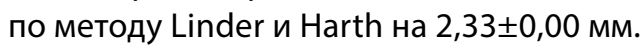

Подтверждено, что у людей с нормодонтными зубными дугами при долихогнатии определяется «высокий» торк передних зубов, а при брахигнатии - низкий. У людей долихогнатическими типами зубных дуг в связи с этим отмечается увеличение глубины дуги из-за протрузионного положения резцов. При брахигнатии отмечается их ретрузионное положение и, следовательно, уменьшение глубины переднего отдела зубной дуги. Таким образом, из общепринятых методов исследования трансверсальных размеров, при обследовании людей с нормодонтными мезогнатическими формами зубных дуг, более приемлем метод Pont.

Возможно использование метода Korkhaus у людей с мезогнатическими нормодонтными типами зубных систем для оценки сагиттальных размеров. Существенные погрешности при всех типах зубных дуг имел Метод Linder и Harth, это отражается на выборе методов и определении эффективности ортодонтического лечения пациентов с нормодонтными зубными системами. 
При мезогнатии ширина зубных дуг в области премоляров были шире, чем рассчитанные по методу Pont

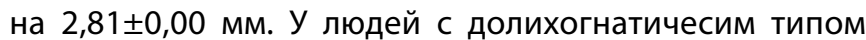
зубных дуг трансверсальных размеров зубных дуг в области премоляров были меньше, чем рассчитанные по методу Pont на 5,42 $\pm 0,00$ мм.

Также имели место особенности, рассчитанные по методу Linder и Harth трансверсальные размеры зубных дуг в области премоляров. Фактические величины трансверсальных размеров зубных дуг в области премоляров были шире, чем рассчитанные по методу

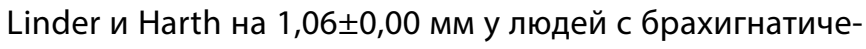
ским типом зубных дуг.

Не имела достоверных различий с показателями, рассчитанными по методу Linder и Harth ширина зубных дуг в области премоляров при мезогнатии. Трансверсальные размеры зубных дуг в области премоляров были меньше, чем рассчитанные по методу Linder

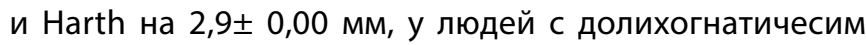
типом зубных дуг.

Рассчитанная по методу Korkhaus глубина переднего отдела зубной дуги, соответствовала расчетным показателям при брахигнатических макродонтных типах зубной системы.

В тоже время для мезо- и долихогнатии было характерно увеличение глубины зубной дуги и разница между расчетными и фактическими показателями

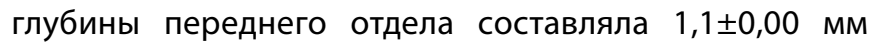
и 1,75 $\pm 0,00$ мм соответственно.

Является логическим и соответствует данным специалистов Несоответствие фактических величин расчетным показателям глубины зубной дуги по Korkhaus.

Было доказано, что «высокий» торк передних зубов у людей с макродонтными зубными дугами определяется при мезо- и долихогнатии, в связи с чем выявлено увеличение глубины дуги из-за протрузионного положения резцов у людей с мезо- и долихогнатическими типами зубных дуг.

При обследовании пациентов с макродонтными мезогнатическими формами зубных дуг из стандартных методов исследования трансверсальных размеров, более применим метод Harth и Linder.

При обследовании пациентов с макродонтными брахигнатическими типами зубных дуг использовали метод Pont. Метод Korkhaus для оценки сагиттальных размеров применим только у людей с брахигнатическими макродонтными типами зубных систем.
При использовании метода Pont были выявлены существенные погрешности при мезо- и долихогнатических типах зубных дуг, что может сказываться на выборе методов и определении эффективности ортодонтического лечения людей с макродонтными типами зубных системам.

Трансверсальные размеры зубных дуг в области премоляров, которые определялись по методу Harth и Linder тоже имели следующие особенности. У людей с брахигнатическим типом зубных дуг в области премоляров фактические величины трансверсальных размеров зубных дуг были шире, чем величины, рассчитанные

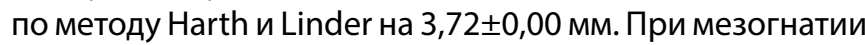
ширина зубных дуг в области премоляров не имела существенных различий с показателями, рассчитанными по методу Harth и Linder. У людей с долихогнатическим типом зубных систем трансверсальные размеры зубных дуг в области премоляров имели меньшую величину, чем

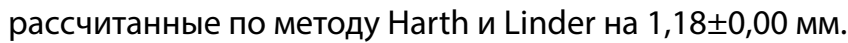

Величина переднего отдела зубной дуги, определенная по методу Korkhaus, не отличалась от показателей, характерным для долихогнатических микрофонных типов зубной системы. У пациентов с для мезо- и брахигнатией было выявлено уменьшение величины глубины зубной дуги. Разница между расчетными и фактическими показателями величины глубины переднего отдела

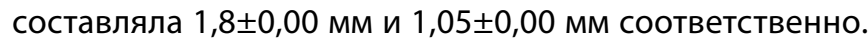
Несоответствие параметров фактических величин расчетным показателям глубины зубной дуги, определённых методом Korkhaus является соответствует данным специалистов (Орлова И.В., 2016). Было выявлено, что у пациентов с макродонтными зубными дугами при мезо- и брахигнатии установлен «низкий» торк передних зубов. В результате отмечено укорочение зубной дуги из-за ретрузионного положения резцов у людей с мезо- и брахигнатическим типами зубных систем.

Были сделаны выводы, что при обследовании пациентов с микродонтными мезогнатическими формами зубных дуг из общепринятых методов определения трансверсальных размеров, оптимален в применении метод Pont и Linder-Harth. Для определения сагиттальных размеров допустимо использование метода Korkhaus у пациентов с долихогнатическими макродонтными типами зубных дуг.

Выполненное исследование дало нам возможность предложить дополнительные методы исследования и оценить их эффективность у людей с различными дентальными и гнатическими типами лица и зубных дуг.

У обследованных людей при сравнительном анализе зубочелюстных и лицевых параметров было опре- 
делено, что основным показателем дентального типа лица и зубных дуг были диагональные размеры лица (t-sn), в независимости от величины ширины лица. При цифровом показателе величины диагональных размеров в 122-130 мм определялся нормодонтный тип лица. При этом сумма ширины коронок 14 зубов в среднем составляла от 112 до 118 мм, а модуль коронок был от 10,6 до 11 мм. Уменьшение значений этих величин было характерно для микродонтизма, а увеличение для макродонтизма. Показателем, определяющим гнатический тип лица было процентное отношение диагональных размеров к трансверсальным (t-t). Значение величины гнатического индекса лица составляло от $83 \%$ до 92\% при мезогнатическом типе лица, независимо от принадлежности к дентальному типу.

Значение величины дентального индекса (отношение полусуммы 14 зубов к ширине зубной дуги между вторыми молярами) определялось в цифровом диапазоне от 0,92 до 0,97. Уменьшение значения величины свойственно брахигнатии, а увеличение этого значения- долихогнатии. У людей с физиологической окклюзией типы зубных дуг и лица были идентичны.

Отношение суммы семи зубов половины зубной дуги к фронтально-молярной диагонали составило при всех типах зубных дуг 1,06. Это позволило данный размер характеризовать как диагональный индекс зубной дуги и применить его для оптимизации методов диагностики аномалий зубных дуг. Глубина зубной дуги рассчитывалась как катет прямоугольного треугольника.

Сравнение расчетных показателей с фактическими величинами выявило их соответствие при всех типах зубных дуг, что дало нам возможность использовать результаты для повышения эффективности методов диагностики и выбора наиболее приемлемых методов ортодонтического лечения.

У пациентов с нормодонтизмом постоянных зубов наблюдались разные гнатические варианты формы зубных дуг (мезогнатические, долихогнатические и брахигнатические). Учитывая рекомендации специалистов при ортодонтическом лечении пациентов с нормодонтными мезогнатическими типами зубных дуг и лица использовалась стандартная пропись брекетов и средние размеры металлических дуг.

У пациентов с нормодонтным долихогнатичеким типом зубных дуг и лица применялась пропись брекетов с «высоким» торком, а дуги были малого размера. Вместе с тем, при нормодонтном брахигнатическом типе использовалась пропись брекетов с «низким» торком, но дуги были большого размера. Результатом практически всех случаев лечения было достигнуто получение физиологической окклюзии с улучшением эстетики лица.

При макродонтизме постоянных зубов и мезогнатическими типами лица и зубных дуг мы использовали брекеты с «высоким» торком и большие размеры металлических дуг.

При макродонтном долихогнатичеком типе лица и зубных дуг мы применяли пропись брекетов с «высоким» торком, но дуги были среднего размера.

Между тем, при макродонтном брахигнатическом типе лица и зубных дуг пропись брекетов была со «стандартным» торком, а дуги- большого размера. Практически во всех клинических случаях было достигнуто получение физиологической окклюзии и параметров зубных дуг, соответствующих размерам, полученных у людей группы сравнения.

При ортодонтическом лечении людей с микродонтными мезогнатическими типами лица и зубных дуг применялись брекеты с «низким» торком и малые размеры металлических дуг.

При микродонтном долихогнатичеком типе использовалась стандартная пропись брекетов, и дуги были малого размера.

При микродонтном брахигнатическом типе употреблялась пропись брекетов с «низким» торком, а дуги были среднего размера. Практически во всех клинических случаях результатом было получение физиологической окклюзии и параметров зубных дуг, соответствующих размерам, зафиксированных у пациентов группы сравнения.

Результаты применяемого нами ортодонтического лечения, которое проводилось у пациентов с учетом оптимизации методов диагностики и прогнозирования формы и размеров зубных дуг, показали, что основные линейные и угловые параметры челюстно-лицевой области улучшились и окклюзионные взаимоотношения соответствовали основным «ключам» физиологической окклюзии.

\section{Выво $\triangle \mathrm{b}$}

1. Алгоритм прогнозирования основных параметров зубных дуг при их аномалиях содержал в себе несколько последовательных этапов: цефалометрию, одонтометрию и измерение основных параметров зубных дуг с последующим сравнительным анализом. Нормодонтному типу лица соответствовали цифровые параметры ди- 
агонали от 122 до 130 мм. Гнатический индекс лица от 83 до 93 был характерен для мезогнатического типа лица. Отношение длины верхней

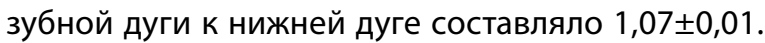
Фациально-молярный коэффициент составляет 2,3 $\pm 0,05$ и предназначался для оценки ширины зубной дуги между вторыми верхними молярами. Межчелюстной молярный коэффициент составлял 1,1 и был предназначен для определения ширины нижней зубной дуги. Представленный алгоритм методов исследования применим для прогнозирования формы и размеров при различных дентальных и гнатических типах зубных дуг.

2. Дентальный тип зубных дуг советуем определять при сравнении трех основных показателей: диагональ лица, сумма ширины коронок четырнадцати зубов и средний модуль коронок моляров.

3. Гнатический тип лица предлагаем сравнивать с гнатическим типом зубных дуг для определения несоответствия указанных параметров.

\section{ЛИТЕРАТУРА}

1. Ведешина Э.Г., Доменюк Д.А., Дмитриенко С.В. Анатомические особенности инклинации и ангуляции постоянных зубов у людей с различными типами мезогнатических зубочелюстных дуг // Кубанский научный медицинский вестник. 2016. № 1 (156). С. 16-23.

2. Ведешина Э.Г., Доменюк Д.А., Дмитриенко С.В. Особенности долихогнатических зубных дуг у людей с различными вариантами размеров зубов // Кубанский научный медицинский вестник, 2016. - № 1. (156). - С. 39-46.

3. Доменюк Д.А., Коробкеев А.А., Лепилин А.В., Ведешина Э.Г., Дмитриенко С.В. Методы определения индивидуальных размеров зубных дуг по морфометричнеским параметрам челюстно-лицевой области. Ставрополь: Изд-во СтГМУ,2016. - 160 с.

4. Eslamipour F., Afshari Z., Najimi A. Prevalence of Malocclusion in Permanent Dentition of Iranian Population: A review Article // Iran. J. Public. Health. 2018. - Vol. 47. — № 2. P. 178-187.

5. Fischev S.B., Puzdyryova M.N., Dmitrienko S.V., Domenyuk D.A., Kondratyuk A.A. Morphological features of dentofacial area in peoples with dental arch issues combined with occlusion anomalies // Archiv EuroMedica. - 2019. — T. 9.— № 1.— P. 162-163.

6. Lepilin A.V., Fomin I.V., Domenyuk D.A., Dmitrienko S.V., Budaychiev G.M-A. diagnostic value of cephalometric parameters at graphic reproduction of tooth dental arches in primary teeth occlusion // Archiv euromedica.— 2018. - V.8. — № 1.— P. 37-38

7. Shen L. He F., Zhang C. Prevalence of malocclusion in primary dentition in mainland China, 1988-2017: a systematic review and meta-analysis // Sci. Rep.2018. - Vol. 8. — № 1.—P. 4716.

8. Singh S., Sharma A., Sandhu N. Prevalence of malocclusion and orthodontic treatment needs in school going children of Nalagarh, Himachal Pradesh, India // J. Dent. Res. - 2016. — Vol. 27.— № 3.—P. 317-322.

( Пуздырева Маргарита Николаевна ( seven-spb@yandex.ru ), Рожкова Мария Геннадьевна ( rozmaria2010@yandex.ru ),

Фищев Сергей Борисович ( super.kant@yandex.ru), Лепилин Александр Викторович ( lepilins@mail.ru ),

Севастьянов Аркадий Владимирович ( ardy.dkr@mail.ru ),Орлова Ирина Викторовна ( orisha@mail.ru ),

Субботин Роман Сергеевич ( roma.seregin.92@mail.ru ), Попов Владимир Петрович (vpopov5@mail.ru ).

Журнал «Современная наука: актуальные проблемы теории и практики» 